\title{
Keefektifan Pemanfaatan dan Arah Pengembangan Laboratorium Prestasi dan Kondisi Fisik FIK UNY
}

\author{
Riky Dwihandaka ${ }^{1}$, Sumarjo ${ }^{2}$ \\ ${ }^{1}$ Pendidikan Olahraga, ${ }^{2}$ Pendidikan Kesehatan dan Rekreasi FIK UNY. Jl. Colombo No. 1 Yogyakarta, 55281, \\ Indonesia \\ * Coressponding Author. E-mail: rikydwihandaka@uny.ac.id
}

\begin{abstract}
This study aims to reveal the effectiveness of utilization and to find out the direction of laboratory development of achievement and physical conditions in the Faculty of Sports Science, which consists of the level of use and completeness of laboratory infrastructure, laboratory management skills, managerial abilities, individual abilities, and student attitudes towards the direction of laboratory development. This research is a qualitative research. The qualitative data collection method used is the data triangulation method which consists of: 1) Focus group discussion (FGD) for students (6 people/group), and 2) Non-participant observation in laboratory settings. The population of this study were all odd semester students who used the achievement laboratory and the physical condition of FIK UNY. The number of samples is based on the saturation of themes in focus group discussions and in-depth interviews. The sample selection of students was carried out based on convenience sampling technique, while in-depth interviews with laboratory managers used criterion sampling techniques. Data analysis used three stages consisting of: 1) data reduction, 2) reconstructive data and 3) thematic analysis. Based on the research that has been done, the results show that FIK UNY students feel that the existence of an achievement laboratory and physical condition is very useful both in its use in lectures, training and research. In increasing the use of laboratory facilities, performance and physical conditions are emphasized on their use, management, maintenance and maintenance. Laboratory achievements need to be promoted and for laboratories in physical condition, staff or laboratory personnel need to be added. The development of performance laboratories and physical conditions is directed towards maintenance and maintenance as well as the construction of a wider and more integrated building.
\end{abstract}

Key words: utilization, development, laboratory

\begin{abstract}
Abstrak
Penelitian ini bertujuan untuk mengungkapkan keefektifan pemanfaatan dan mengetahui arah pengembangan laboratorium prestasi dan kondisi fisik di Fakultas Ilmu Keolahragaan, yang terdiri dari tingkat penggunaan dan kelengkapan sarana prasarana laboratorium, kemampuan pengelolaan laboratorium, kemampuan manajerial, kemampuan individual, dan sikap mahasiswa terhadap arah pengembangan laboratorium. Penelitian ini merupakan penelitian kualitatif. Metode pengumpulan data kualitatif yang dipergunakan adalah metode triangulasi data yang terdiri dari :1) Focus group discusion (FGD) pada mahasiswa (6 orang/kelompok), dan 2) Observasi non-participant pada setting laboratorium. Populasi penelitian ini adalah seluruh mahasiswa semester gasal yang menggunakan laboratorium prestasi dan kondisi fisik FIK UNY. Jumlah sampel didasarkan pada saturasi tema pada focus group discussion maupun in-depth interview. Pemilihan sampel pada mahasiswa dilakukan berdasarkan teknik convenience sampling sedangkan pada in-depth interview dengan pengelola laboratorium dengan mempergunakan teknik criterion sampling. Analisis data menggunakan tiga tahap terdiri dari: 1) data reduction, 2) data reconstrucsi dan 3) analisis thematic. Berdasarkan penelitian yang telah dilakukan diperoleh hasil bahwa mahasiswa FIK UNY merasa keberadaan laboratorium prestasi dan kondisi fisik sangat bermanfaat baik dalam penggunaannya dalam kuliah, latihan maupun penelitian. Dalam meningkatkan penggunaan sarana laboratorium prestasi dan kondisi fisik ditekankan pada pemakaian, pengelolaan, perawatan dan pemeliharaannya. Laboratorium prestasi perlu ditingkatkan promosinya dan untuk laboratorium kondisi fisik perlu ditambahkan staf atau petugas tenaga laboratorium. Pengembangan laboratorium prestasi dan kondisi fisik diarahkan dalam pemeliharaan dan perawatan serta pembuatan gedung yang lebih luas dan terpadu.
\end{abstract}

Kata kunci: pemanfaatan, pengembangan, laboratorium 


\section{PENDAHULUAN}

Laboratorium merupakan salah satu komponen yang sangat penting dalam mewujudkan fungsi tridharma perguruan tinggi. Laboratorium merupakan sarana bagi mahasiswa dan dosen untuk melakukan kegiatan pendidikan, penelitian, dan layanan pada masyarakat. Kertiasa (2006: 1) mengartikan bahwa laboratorium adalah tempat bekerja untuk mengadakan percobaan atau penyelidikan dalam bidang ilmu tertentu seperti fisika, kimia, biologi dan sebagainya. Dalam pengertian terbatas laboratorium adalah suatu ruangan tertutup dimana percobaan dan penelitian dilakukan, tempat ini dapat merupakan suatu ruangan tertutup, kamar atau ruangan terbuka (Depdikbud, 1995: 7). Dalam Kamus Besar Bahasa Indonesia (Poerwadarminta, 2002) laboratorium diartikan sebagai tempat mengadakan percobaan (penyelidikan dan sebagainya). Suatu lembaga kependidikan diwajibkan memiliki sarana dan prasarana penunjang untuk proses pembelajaran sehingga dapat mencapai tujuan pembelajaran.

Sebagaimana tercantum dalam Pasal 42 ayat (2) Peraturan Pemerintah Nomor 19 Tahun 2005 tentang Standar Nasional Pendidikan, dinyatakan bahwa: "Setiap satuan pendidikan wajib memiliki prasarana yang meliputi lahan, ruang kelas, ruang pimpinan satuan pendidikan, ruang pendidik, ruang tata usaha, ruang perpustakaan, ruang laboratorium, ruang bengkel kerja, ruang unit produksi, ruang kantin, instalasi daya dan jasa, tempat berolahraga, tempat beribadah, tempat bermain, tempat berekreasi dan ruang atau tempat lain yang diperlukan untuk menunjang proses pembelajaran yang teratur dan berkelanjutan". Laboratorium di universitas dikenal sebagai teaching laboratory atau lab pembelajaran. Pada program studi bidang sains, aktivitas di laboratorium menjadi komponen substansial pembelajaran (Reid \& Shah, 2007: 173). Peraturan Menteri Pendidikan dan Kebudayaan Republik Indonesia Nomor 3 Tahun 2020 Tentang Standar Nasional Pendidikan Tinggi, Pasal 33 dan 35 menyebutkan bahwa laboratorium merupakan salah satu standar prasarana pembelajaran di perguruan tinggi dalam rangka pemenuhan capaian pembelajaran lulusan. Laboratorium di perguruan tinggi adalah sarana yang seyogyanya mendukung penyelenggaraan ketiga ranah dalam tri darma perguruan tinggi (Utari, 2017: 1).

Tarmizi (2005), mengemukakan bahwa fungsi laboratorium adalah sebagai tempat untuk menguatkan/memberikan kepastian keterangan (informasi), menentukan hubungan sebab akibat (casualitas), membuktikan benar tidaknya faktor-faktor fenomena-fenomena tertentu, membuat hukum atau dalil dari suatu fenomena apabila sudah dibuktikan kebenarannya, mempraktekan sesuatu yang diketahui, mengembangkan keterampilan, memberikan latihan menggunakan metode ilmiah dalam memecahkan problem dan untuk melaksanakan penelitian perorangan. Seperti pendapat Hofstein dan Naaman (2007) yang mengemukakan bahwa keberadaan laboratorium (kegiatan praktikum) di sekolah dapat mendukung kegiatan pembelajaran serta mencapai tiga ranah tujuan pendidikan yaitu kognitif, afektif dan psikomotorik. Emda (2014: 220-221) menyatakan bahwa 
secara garis besar fungsi laboratorium adalah : 1) Memberikan kelengkapan bagi pelajaran yang telah diterima sehingga antara teori dan praktek bukan merupakan dua hal yang terpisah, 2) Memberikan keterampilan kerja ilmiah bagi mahasiswa/siswa, 3) Memberikan dan memupuk keberanian untuk mencari hakikat keberanian ilmiah dari suatu objek dalam lingkungan alam dan lingkungan sosial, 4) Menambah keterampilan dalam menggunakan alat dan media yang tersedia untuk mencari dan menemukan kebenaran, 5) Memupuk rasa ingin tahu mahasiswa/siswa sebagai modal sikap ilmiah seorang calon ilmuan, 6) Memupuk dan membina rasa percaya diri sebagai akibat keterampilan yang diperoleh, penemuan yang didapat dalam proses kegiatan kerja laboratorium. Pengelolaan laboratorium juga penting untuk diperhatikan yang secara garis besar Rustaman, (2003) berpendapat bahwa pengelolaan laboratorium dibedakan menjadi kegiatan pemeliharaan, penyediaan, dan peningkatan daya guna laboratorium. Solihatin dan Raharjo (2007), membagi struktur organisasi laboratorium pada umumnya terdiri dari:

a. Kepala Laboratorium

Kepala laboratorium biasanya dijabat yang memiliki kualifikasi pendidikan sesuai dengan bidang keahliannya dan memiliki pengetahuan serta keterampilan dalam mengelola laboratorium.

b. Tenaga Teknisi

Tenaga teknisi merupakan seseorang yang memiliki kemampuan secara profesional untuk menjalankan, mengoperasikan, dan memelihara serta mengembangkan perlengkapan sehingga laboratorium dapat untuk digunakan.

c. Tenaga Laboratorium

Tenaga laboratorium merupakan seseorang yang memiliki kemampuan profesional untuk menyelenggarakan kegiatan-kegiatan di laboratorium yang meliputi penelitian, pengembangan dan pelatihan serta layanan pada suatu bidang ilmu tertentu. Tugas utamanya adalah membantu terselenggarakannya kegiatan laboratorium.

FIK UNY memiliki laboratorium prestasi dan kondisi fisik. Laboratorium prestasi dan kondisi fisik yang dimiliki FIK UNY merupakan salah satu fasilitas yang sangat mendukung pembinaan olahraga di DIY. Keberadaaan laboratorium prestasi dan kondisi fisik FIK UNY digunakan sebagai laboratorium untuk melihat peningkatan dan perkembangan kondisi fisik dari atlet. Kegiatan tes dan pengukuran kesehatan dan kondisi fisik banyak dilakukan di laboratorium prestasi dan kondisi fisik FIK UNY. Pemanfaatan laboratorium prestasi dan kondisi fisik saat ini hanya digunakan untuk proses perkuliahan tertentu yang berkaitan dengan tes dan pengukuran, selain itu laboratorium prestasi dan kondisi fisik juga memfasilitasi dalam mengevaluasi prestasi atlet di tingkat Pengkab, Pengprov dan klub. Kegiatan pengukuran yang berkaitan dengan kesehatan dan kondisi fisik masyarakat umum belum bisa memfasilitasi, dikarenakan tempat, ruangan dan peralatan yang terbatas. Laboratorium prestasi dan kondisi fisik dalam kegiatan perkuliahan dimanfaatkan oleh dosen dan mahasiswa dalam melakukaan perkuliahan praktek dengan menggunakan alat secara langsung untuk mengetahui tes dan pengukuran secara tepat, dengan adanya perkuliahan terkait 
mahasiswa nantinya akan mengetahui, memahami dan terampil dalam melakukan tes dan pengukuran terkait dengan kesehatan dan kondisi fisik.

Mata kuliah Tes dan Pengukuran di FIK UNY sudah memiliki wadah untuk pengembangannya yang berupa laboratorium prestasi dan kondisi fisik. Fokus sasaran pengembangan awal yang sudah dilakukan pada laboratorium tersebut adalah pengembangan teknik pembelajaran. Sasaran tersebut diutamakan dengan tujuan optimalisasi sarana dan prasarana yang dimiliki, agar seluas-luasnya dapat diakses dan dimanfaatkan oleh mahasiswa bagi pengembanagan dirinya. Fokus selanjutnya yang berupa pengembangan keilmuan olahraga belum dapat banyak dikerjakan karena terkendala dengan keterbatasan sumber daya manusia serta keterbatasan dukungan fasilitas pengembangan keilmuan.

Penelitian ini merupakan penelitian kualitatif yang merupakan bagian dari dukungan pada proses pengembangan laboratorium prestasi dan kondisi fisik dengan jalan membantu memberikan evaluasi diri tentang usaha kebermanfaatan fasilitas laboratorium yang selama ini telah dikerjakan. Penelitian ini akan mengeksplorasi tentang sikap mahasiswa dan dosen tentang keefektifan pemanfaatan fasilitas laboratorium dan arah pengembangan yang mereka butuhkan. Pemanfaatan serta pengembangan laboratorium prestasi dan kondisi fisik ini merupakan sasaran akhir yang ingin diupayakan dalam penelitian ini. Pada akhirnya kebermanfaatan dan pengembangan laboratorium prestasi dan kondisi fisik di FIK UNY diharapkan dapat meningkatkan kualitas proses pembelajaran serta kajian keilmuan yang bermanfaat bagi pengembangan diri mahasiswa maupun pengajar.

\section{METODE}

\section{Desain dan Metode Penelitian}

Penelitian ini merupakan penelitian kualitatif. Penelitian kualitatif ini diharapkan dapat memberikan gambaran tentang persepsi mahasiswa dan dosen tentang tingkat penggunaan sarana laboratorium serta arah pengembangan laboratorium yang mereka harapkan. Metode pengumpulan data kualitatif yang dipergunakan adalah metode triangulasi data yang terdiri dari :

1. Focus group discusion (FGD) pada kelompok mahasiswa (6-8 orang/kelompok).

2. In-depth interview pada pengelola laboratorium (dosen atau tenaga lab)

3. Observasi non-participant pada setting laboratorium.

\section{Populasi dan Sampel Penelitian}

Populasi penelitian ini adalah seluruh mahasiswa semester genap yang menggunakan laboratorium prestasi dan kondisi fisik FIK UNY. Jumlah sampel didasarkan pada saturasi tema pada focus group discussion maupun in-depth interview. Pemilihan sampel pada mahasiswa dilakukan berdasarkan teknik convenience sampling sedangkan pada in-depth interview dengan pengelola laboratorium dengan mempergunakan teknik criterion sampling. Semua calon responden akan diberikan informasi tentang tujuan penelitian dan dimintai kesediaannya untuk berpartisipasi. Pada 
responden yang setuju untuk berperan serta dalam penelitian ini akan dilakukan FGD maupun wawancara di tempat dan waktu yang disepakati bersama.

\section{Instrumen Penelitian}

Pada penelitian kualitatif, instrumen penelitian adalah peneliti itu sendiri yang dalam hal ini dibantu dengan daftar tema (theme list) yang telah disiapkan. Daftar tema tersebut dipersiapkan oleh tim peneliti sebelum pelaksanaan FGD dan in-depth interview dan akan dikombinasikan dengan tema yang terbentuk selama proses FGD maupun in-depth interview. Data pada FGD dan in-depth interview direkam kemudian ditranskrip. Data hasil observasi pada observasi non-participant dicatat dalam catatan lapangan (field-notes).

\section{Analisis Data}

Proses pertama analisis adalah data reduction di mana hasil transkrip data FGD dan interview serta catatan lapangan pada observasi direduksi kemudian dipilah berdasarkan daftar tema awal dan tema yang muncul pada saat pengambilan data. Proses selanjutnya adalah data reconstruction dan analisis thematic. Analisis thematic dilakukan dengan berulang kali membaca hasil transkrip, membandingkan dan mengkontraskan data yang diperoleh dari semua responden pada satu tema dan antar tema dengan mempergunakan bubbling technique. Pada tahap akhir ditarik kesimpulan terakhir tentang bagaimana hubungan antara satu tema dengan tema yang lain pada keseluruhan responden serta inventarisasi semua temuan-temuan penting.

\section{HASIL DAN PEMBAHASAN}

\section{Kebermanfaatan Laboratorium}

\section{a. Laboratorium Prestasi}

Sebagian besar pengalaman mahasiswa dalam mengunakan laboratorium prestasi pada saat perkuliahan dan penelitian. Laboratorium prestasi sudah dikelola dengan baik, administrasi juga sudah dikelola, prosedur penggunaan dan peminjaman alat sudah ada. Dengan adanya kuliah di laboratorium prestasi sangat menambah wawasan yang berkaitan dengan alat-alat laboratorium, khususnya yang berkaitan dengan prestasi olahraga. Sedangkan dari segi kebermanfaatan laboratorium prestasi sangat bermanfaat dalam proses perkuliahan, proses penelitian dan pengambilan data para atlet dari dalam maupun dari luar kampus.

Penggunaan laboratorium prestasi dari FGD didapatkan hasil bahwa sarana laboratorium prestasi sudah optimal penggunaannya, di samping dipergunakan untuk perkuliahan, juga dipergunakan untuk penelitian, baik mahasiswa yang melaksanakan skripsi maupun penelitian para dosen. Hal-hal yang menjadi kendala dalam penggunaan laboratorium prestasi dari hasil FGD didapatkan bahwa dalam penggunaannya tidak ada kendala karena prosedurnya sudah cukup mudah di samping itu setiap alat juga sudah ada petunjuk penggunaannya.

\section{b. Laboratorium Kondisi Fisik}


Sebagian besar pengalaman mahasiswa dalam mengunakan laboratorium kondisi fisik pada saat mengikuti perkuliahan dan penerapkan program latihan. Kualitas pengelolaan laboratorium kondisi fisik pada saat ini belum optimal dalam penggunannya. Sedangkan dari segi kebermanfaatan mahasiswa mengungkapkan bahwa laboratorium kondisi fisik sangat bermanfaat dalam membantu dan menunjang prestasi mahasiswa di bidang olahraga baik dalam meningkatkan prestasi dan menjaga kebugaran mahasiswa. Selain itu juga dapat menambah pengalaman mahasiswa dalam menyusun program latihan yang divariasikan dengan menggunakan alat beban.

Penggunaan laboratorium kondisi fisik dalam pratikum atau kegiatan penelitian, dari FGD didapatkan hasil bahwa penggunaannya belum optimal karena beberapa alat beban banyak yang berkarat, alat beban seperti barbel dan dumbel tidak lengkap dan itu sangat kurang, selain itu perawatan alat beban tidak ada, contohnya seperti alat pembersih. Di sisi lain, mereka juga menyatakan bahwa yang menjadi kendala dalam penggunaan laboratorium kondisi fisik, yaitu tidak ada alat yang digunakan untuk latihan kardiorespirasi, sehingga di laboratorium kondisi disik perlu ditambah alat yang bisa untuk latihan kardiorespirasi seperti treadmil dan sepeda statis. Selain itu banyak peralatan yang kurang terawat, seret dan berkarat.

\section{Optimalisasi Penggunaan Sarana Laboratorium}

\section{a. Laboratorium Prestasi}

Laboratorium prestasi dalam mengoptimalisasi penggunaanya dengan meningkatkan promosi baik didalam maupun diluar kampus, karena keberadaan laboratorium prestasi di FIK UNY di lingkungan kampus sendiri yaitu civitas akademik FIK UNY baik mahasiswa, karyawan dan dosen belum mengetahui secara familier keberadaan laboratorium prestasi. Sehingga dengan adanya promosi baik berupa leaflet atau sosial media dapat memberikan informasi bagi calon pengguna yang ingin memanfaatkan laboratorium prestasi baik dari dalam maupun dari luar kampus.

\section{b. Laboratorium Kondisi Fisik}

Dalam meningkatkan penggunaan sarana laboratorium kondisi fisik harus ditambahkan staf atau petugas tenaga laboratorium yang dapat mengurusi perawatan dan pemantauan dalam sisi penggunaannya, sehingga administrasi, prosedur dan jadwal pemakaian bisa termonitoring dengan mudah. Dengan adanya petugas laboratorium perawatan alat dapat terpelihara dengan baik di samping itu setiap yang menggunakan laboratorium dapat termonitor dengan baik, karena sampai saat ini masih banyak para pengguna yang menggunakan laboratorium kondisi fisik yang berasal dari luar $\mathrm{UNY}$.

\section{Arah Pengembangan Laboratorium}




\section{a. Laboratorium Prestasi}

Harapan pengembangan laboratorium prestasi selalu dapat membantu mahasiswa, baik untuk kegiatan perkuliahan maupun kegiatan penelitian, sehingga mahasiswa dapat menambah wawasan dan pengalaman, selain itu juga membantu penelitian di dalam penyelesaian skripsi atau tugas akhir. Sarana yang dimiliki laboratorium prestasi sudah bisa dikatakan layak, walaupun ada beberapa alat yang kondisinya sudah tidak optimal lagi, dan jumlahnya yang hanya satu. Beberapa alat perlu diperbaharui, karena bisa dikatakan sudah berumur. Beberapa alat juga dalam kondisi rusak, sehingga perlu perbaikan. Untuk ruangan yang terlalu sempit dan kurang tersentral, sehingga perlu dibuat gedung yang luas dan terpadu. Selain itu perlu dibuat promosi baik melalui media cetak atau media sosial. Beberapa alat yang jumlahnya hanya satu perlu ditambah.

\section{b. Laboratorium Kondisi Fisik}

Harapan pengembangan laboratorium kondisi fisik agar selalu ditingkatkan dalam pemeliharan dan perawatannya. Setiap dua hari sekali dibersihkan alat dan kebersihan laboratoriumnya. Alat yang berkarat disarankan untuk diperbaiki kalau tidak bisa diperbaiki diganti dengan yang baru. Sarana laboratorium kondisi fisik saat ini belum layak dalam memenuhi kebutuhan perkuliahan dan penelitian karena terdapat alat beban yang sudah berkarat, ada yang seret dan tempatnya sedikit kotor. Sarana dan prasarana laboratorium kondisi fisik sebaiknya perlu ditambah alat seperti treadmil, sepeda statis, dumbel, barbel, squat, leg curl, matras, dan bola besar. Sedangkan yang perlu ditingkatkan penambahan petugas untuk membantu dalam permeliharaan dan perawatan laboratorium.

\section{Pembahasan}

Mahasiswa FIK UNY merasa bahwa keberadaan laboratorium prestasi dan kondisi fisik sangat bermanfaat baik dalam penggunaanya dalam kuliah, latihan maupun penelitian. Mereka mengemukakan bahwa laboratorium kondisi fisik sangat bermanfaat dalam membantu dan menunjang prestasi mahasiswa di bidang olahraga baik dalam meningkatkan prestasi dan menjaga kebugaran mahasiswa. Selain itu juga dapat menambah pengalaman mahasiswa dalam menyusun program latihan yang divariasikan dengan menggunakan alat beban. Sedangkan manfaat laboratorium prestasi sangat menambah wawasan yang berkaitan dengan alat-alat laboratorium, khususnya yang berkaitan dengan prestasi olahraga. Sedangkan dari segi kebermanfaatan laboratorium prestasi sangat bermanfaat dalam proses perkuliahan, proses penelitian dan pengambilan data para atlet dari dalam maupun dari luar kampus.

Dalam meningkatkan penggunaan sarana laboratorium prestasi dan kondisi fisik, perlu ditingkatkan lagi khususnya pada laboratorium kondisi fisik yang harus ditambahkan staf atau petugas tenaga laboratorium sehingga dapat mengurusi perawatan, pemantauan dalam sisi penggunaanya, administrasi, prosedur dan jadwal pemakaian bisa termonitoring dengan mudah. Sedangkan laboratorium prestasi dalam mengoptimalisasi penggunaanya dengan meningkatkan promosi baik didalam maupun di luar kampus, sehingga dengan adanya promosi baik berupa leaflet atau sosial 
media dapat memberikan informasi bagi calon pengguna yang ingin memanfaatkan laboratorium prestasi baik dari dalam maupun dari luar kampus.

Harapan pengembangan laboratorium kondisi fisik agar selalu ditingkatkan dalam pemeliharan dan perawatannya. Sarana dan prasarana laboratorium kondisi fisik sebaiknya perlu ditambah alat seperti treadmil, sepeda statis, dumbel, barbel, squat, leg curl, matras, dan bola besar. Sedangkan yang perlu ditingkatkan penambahan petugas untuk membantu dalam permeliharaan dan perawatan laboratorium. Sedangkan harapan pengembangan laboratorium prestasi selalu dapat membantu mahasiswa, baik untuk kegiatan perkuliahan maupun kegiatan penelitian, sehingga mahasiswa dapat menambah wawasan dan pengalaman, selain itu juga membantu penelitian di dalam penyelesaian skripsi atau tugas akhir. Arah pengembangan untuk laboratorium prestasi perlu dibuat gedung yang luas dan terpadu. Selain itu perlu dibuat promosi baik melalui media cetak atau media sosial.

\section{KESIMPULAN}

\section{Simpulan}

Mahasiswa FIK UNY merasa bahwa keberadaan laboratorium prestasi dan kondisi fisik sangat bermanfaat baik dalam penggunaannya dalam kuliah, latihan maupun penelitian. Dalam penggunaan sarana laboratorium prestasi dan kondisi fisik perlu ditingkatkan dalam segi pemakaian, pengelolaan, perawatan dan pemeliharaanya. Laboratorium prestasi perlu ditingkatkan promosinya dan untuk laboratorium kondisi fisik perlu ditambahkan staf dan petugas tenaga laboratorium. Arah pengembangan untuk laboratorium prestasi perlu dibuat gedung yang luas dan terpadu. Sedangkan pengembangan laboratorium kondisi fisik diarahkan dalam pemeliharaan dan perawatan.

\section{Saran}

Berdasarkan hasil yang dibahas maka peneliti memberikan beberapa saran sebagai berikut:

1. Dengan adanya tanggapan mahasiswa tentang kefektifan pemanfaatan dan arah pengembangan laboratorium prestasi dan kondisi fisik dapat meningkatkan pengelolaan dan pengembangan laboratorium yang ada di FIK UNY.

2. Disarankan untuk para dosen dan pengelola laboratorium, agar dapat memperhatikan dan meningkatkan proses pemanfaatan dan pengelolaan sehingga dapat bermanfaat terhadap mahasiswa dalam kegiatan yang berhubungan dengan pengajaran, penelitian, dan latihan.

3. Kelemahan dalam penelitian ini hanya terdapat satu variabel yaitu tanggapan mahasiswa sehingga masih diperlukan penelitian lebih lanjut dengan menambah variabel yang berhubungan dengan pemakai laboratorium seperti dosen dan pengelola laboratorium.

\section{DAFTAR PUSTAKA}

Depdikbud. (1995). Pedoman Pendayagunaan Laboratorium dan Alat Pendidikan IPA. Jakarta: Depdikbud. 
Emda, A. (2014). Laboratorium sebagai Sarana Pembelajaran Kimia dalam Meningkatkan Pengetahuan dan Keterampilan Kerja Ilmial. Jurnal Lantanida, Vol. 2 No. 2. DOI: http://dx.doi.org/10.22373/lj.v2i2.1409

Hofstein, A. \& Naaman, R.M. (2007). The Laboratory In Science Education: The State Of The Art. Journal of Chemitry Education and Practice 8 (2):105-107. April 2007, dari http://www.mediapembelajaran.com/index.php?option=com_content\&task=view\&id=7\&Itemid $=2$.

Kertiasa N. (2006). Laboratorium Sekolah dan Pengelolaannya. Jakarta: Pudak Scientific.

Peraturan Menteri Pendidikan dan Kebudayaan Republik Indonesia Nomor 3 Tahun 2020 Tentang Standar Nasional Pendidikan Tinggi.

Peraturan Pemerintah Nomor 19 Tahun 2005 tentang Standar Nasional Pendidikan.

Poerwadarminta. (2002). Kamus Umum Bahasa Indonesia. Jakarta: Balai Pustaka.

Reid, N. \& Shah, I. (2007). The Role of Laboratory Work in University Chemistry. Journal Chemistry Education Research and Practice Vol 8 No 2, 172-185.

Rustaman, N. (2003). Strategi Pembelajaran Biologi. Universitas Terbuka.

Solihatin E., dan Raharjo. (2007). Cooperative Learning. Jakarta: Bumi Aksara.

Tarmizi. (2005). Model-Model Pembelajaran Sains. Jakarta: Grasindo

Utari, R. (2017). Penguatan dan Perluasan Fungsi Laboratorium pada Rumpun Ilmu Sosial di Perguruan Tinggi. Dinamika Pendidikan Volume XXII No 1 Mei 2017. 